\title{
Performance and trend for quality of service in a large HIV/AIDS treatment program in Nigeria
}

Ahmad Aliyu ${ }^{1}$ (1D, Samer El-Kamary², Jessica Brown² ${ }^{2}$ Bruce Agins ${ }^{3}$, Nicaise Ndembi 1,7* Gambo Aliyu ${ }^{4}$, Jibreel Jumare ${ }^{4}$, Babatunde Adelekan ${ }^{5,6}$, Patrick Dakum ${ }^{1,4}$, Alash'le Abimiku, ${ }^{1,4}$ and Manhattan Charurat ${ }^{4}$

\begin{abstract}
Background: As antiretroviral therapy (ART) programs expand access, there is an increase in burden to a healthcare system. These results are reduced provider-patient contact time and poor programmatic and patient outcomes. Quality management offers providers a standardized approach for addressing the appropriateness of care to be applied in resource-limited settings. This study aimed to determine the trend of performance on HIV/AIDS quality management indicators of health facilities providing ART over a period of 5 years.

Methods: The annual performance scores of quality of care (QOC) indicators of 31 health facilities providing ART was extracted from a database covering a period of 5 years (from October 2008 to September 2012). The data are percentages that indicate scores of each health facility assessed based on compliance to National ART guidelines categorized into several indicator domains. A Chi square statistic for the trend, as well as test for departure from the trend line was determined. The $p$ value associated with each indicator provides the significant level for testing an alternative hypothesis that the rate of change over the period considered for that indicator does not equal to zero. The slope of the regression line also gives the magnitude of the rate of change for each indicator by healthcare level across the review period.
\end{abstract}

Results: Generally, performance trends showed improvement across most indicator domains. The highest improvement occurred for "3 month loss to follow-up" and "1 year no-visit", with scores declining from 37 to 3\%, and 42\% to $12 \%$ respectively. However, there was a sharp decline in performance between 2010 and 2012 in weight monitoring of patients $(p<0.01)$, adherence assessment to ARVs $(p<0.01)$ and hematocrit measurements $(p=0.01)$. The aggregate rate of change $\beta$, as obtained from the slope of the trend line is highly significant $(p<0.01)$ for all the quality of care indicators considered, whether improving or declining.

Conclusion: Periodic assessment to determine HIV/AIDS quality of care can guide rapid scale-up of services to achieve universal coverage in resource-limited settings. Determining trends to understand patterns is very useful for improving programmatic and patient outcomes.

Keywords: Quality, Performance, Indicators, ART, Nigeria

\footnotetext{
*Correspondence: nndembi@ihvnigeria.org

${ }^{1}$ Institute of Human Virology, Nigeria, Maina Court, Plot 252 Herbert

Macaulay Way, Central Business District, Garki, Abuja 9396, Nigeria

Full list of author information is available at the end of the article
} 


\section{Background}

Sub-Saharan Africa had a massive scale-up of antiretroviral therapy (ART) coverage from 3.9 million people at the end of 2009 to about 21.7 million as of the end of 2017 , accounting for about $70.5 \%$ of the global number of people receiving HIV treatment in that year [1]. Nigeria has an estimated 3.6 million infected with HIV as of 2010 with 1.4 million of the infected in need of ART, but only about 350,000 had access to lifesaving drugs. By 2017, 3.1 million are infected and 1.04 million are on life-saving ART. Therefore, it is still is an important target to scaleup ART services and implement a continuous quality improvement (CQI) system for standard service delivery necessary to stem the tide and achieve epidemic control [2-4].

The burden of HIV/AIDS epidemic and limited access to ART facilitated the re-emergence of disease conditions such as pulmonary tuberculosis (PTB), in addition to poor quality of life attributable to health and socioeconomic challenges associated with limited access to ART $[5,6]$. However, with increasing access to ART and reduction in morbidity and mortality from HIV/AIDs, the average life expectancy in Nigeria rose from 48 years in 2000 to 54 years in 2018 [7].

Standard ART improves the quality of life (QoL) of HIV/AIDS patients [8-10]. However, improvement of QoL following ARV treatment does not depend only on access and availability of the lifesaving drugs; it also depends on the appropriate execution of recommended components of care including prevention and treatment of opportunistic infections, adherence to treatment and routine monitoring of laboratory investigations, and the clinical follow-up of patients [11-14]. HIV/AIDS requires comprehensive health services similar to those needed for cancer, diabetes, and cardiovascular care [15].

The delivery of HIV/AIDS services in Nigeria started in 2002 with no defined guidelines or clinical standards. However, with increasing access to ARV through international programs like the United States President's Emergency Plan for AIDS Relief (PEPFAR) and Global Fund for AIDS, Tuberculosis, and Malaria (GFATM), clinical practice guidelines are developed to assist care providers in the delivery of standard care needed by HIV/AIDS patients, but compliance from both caregivers and care recipient has become a huge challenge. A study to identify determinants of nonadherence to ART in Southeast Nigeria found $75 \%$ of the respondents not fully adhering to their drug regimen [16].

Global HIV/AIDS programs including PEPFAR and GFATM have worked to develop results-based performance indicators to track achievements towards meeting program goals concerning funding. However, program-level indicators remain incomplete, and a carefully selected set of measures assessing the processes of care delivery collected at 6 to 12 -month intervals, would provide important data to guide quality improvement efforts for standard care delivery of HIV care services $[17,18]$.

The introduction and implementation of HIV qualityNigeria (HIVQUAL-N) was supported by the United States Centers for Disease Control and Prevention (CDC) to promote the delivery of appropriate care and treatment to HIV infected individuals through understanding of the human resource and infrastructure needs, as well as the challenges involved to implement a comprehensive ART program that focuses on adherence to National guidelines for delivery of HIV/AIDS services. This paper reports the application of HIVQUAL, a system developed by New York State Department of Health, AIDS Institute (NYSDOH-AI) to evaluate performance on quality management in one of the largest HIV treatment programs in sub-Saharan Africa (sSA) [19-21].

The objective of this analysis is to determine the performance and trend of quality of care in a large HIV prevention and treatment program in Nigeria.

\section{Methods}

AIDS Care and Treatment in Nigeria (ACTION) program is the largest HIV care and treatment program in Nigeria funded by PEPFAR through the Institute of Human Virology, University of Maryland (IHV-UMD). In the beginning, ACTION program activities, as well as the implementation of HIVQUAL occurred mainly at tertiary health centers where majority of people living with HIV/AIDS (PLWHA) access care and treatment services.

\section{Quality of care indicators development}

The Nigerian HIV quality of care indicators were jointly developed by US CDC, New York State Department of Health AIDS Institute (NYSDoH-AI) supported through PEPFAR/Health Resource Services Administration (HRSA) as HEALTHQUAL, IHV-UMD, Nigeria Federal Ministry of Health (FMoH) and other stakeholders, to monitor health facility-level performance that define optimal patient and program level outcomes.

Data on these indicators are collected annually. For the purpose of this evaluation, selected HIV/AIDS quality indicators (weight monitoring, treatment adherence assessments, anemia screening, liver function tests (LFT), hepatitis B, C screening, and HIV/AIDS care and support assessment, nutritional assessment, no clinic visit within 1 year, loss to follow-up and tuberculosis screening) were considered. The definition of each quality of care indicator is given in Appendix 1. 


\section{Data collection and description}

Four years of annual performance scores of quality of HIV/AIDS care indicators were computed from assessments of 28 tertiary and 3 secondary health facilities providing comprehensive HIV/AIDS care and treatment under the ACTION program. The selection of tertiary centers for HIV care by the ACTION program was to ease access for PLWHA. However, ART services were gradually expanded to several secondary and primary health centers to improve access. Annual audit of sampled patients charts are normally randomly selected at each facility using probability proportional to size sampling that is predetermined to give a $90 \%$ confidence interval with a maximum error margin of $16 \%$ when using the least number of records. Such audit assessments were conducted in 2008, 2009, 2010, and 2012. Due to program transition between UMB-IHV and IHVN, quality audit assessment was not conducted in 2011. To enable trend evaluation and comparison of scores of quality indicators over the years, only health facilities that collected three or more data points were included.

Performance scores were proportions of patients in the audit samples with appropriate care documented based on specific measures of the selected indicators to indicate facility's compliance with National HIV/AIDS ART guidelines. The numerator of each indicator represents the number of patients' charts with documented evidence of compliance to requirements for HIV/AIDS clinical management, while the denominator is the proportionate to size total sample.

\section{Data analysis}

The $p^{\text {trend }}$ command of StataIC 13 statistical software was used to determine trends of performance over the review period. $p^{\text {trend }}$ calculates a Chi square statistic for the trend, as well as test for departure from the trend line. Trend analysis assumes a linear relationship with time; it can detect significant variations over time and identify areas for audit investigation to find solutions, but provides little insight into the root causes of variations. Also, trend analysis does not give normal or baseline benchmarks from which performance can be measured and compared over some time.

The p-value associated with each indicator provides the significant level for testing an alternative hypothesis that the rate of change over the period considered for that indicator does not equal to zero. The slope of the regression line also gives the magnitude of the rate of change for each indicator by healthcare level across the review period, which allows for comparison across the different levels of care. The 95\% confidence interval (CI) for each of the quality indicators were computed by sites and year.

\section{Results}

The performance scores for the selected quality indicators across all facilities evaluated are summarized in Table 1. The aggregate percentage scores of quality indicators over the period under review indicate a significant improvement in all domains. Better improvements are seen in percentage of 3 months loss to follow-up from $46 \%$ [ $95 \%$ CI $43.8-47.4$ ] in 2008 to $12 \%$ [95\% CI 10.6-12.8] in 2012, and severe reduction of patients spending 1 year without visit: from 31\% [95\% CI $29.8-32.8$ ] to $3 \%$ [95\% CI 2.3-5.0] in the same time period. However, there is decrease in performance between 2010 and 2012 in weight monitoring, adherence assessment, and anemia screening. The trend for each indicator is graphically illustrated in Appendix 2.

Table 1 Aggregated scores of HIV/AIDS quality indicators of health facilities from 2008 to 2012

\begin{tabular}{|c|c|c|c|c|c|c|c|c|}
\hline \multirow[t]{2}{*}{ Quality indicators } & \multicolumn{2}{|c|}{2008} & \multicolumn{2}{|c|}{2009} & \multicolumn{2}{|c|}{2010} & \multicolumn{2}{|c|}{2012} \\
\hline & $\%$ & $95 \% \mathrm{Cl}$ & $\%$ & $95 \% \mathrm{Cl}$ & $\%$ & $95 \% \mathrm{Cl}$ & $\%$ & $95 \% \mathrm{Cl}$ \\
\hline Weight monitoring & 76 & $74.8-78.1$ & 79 & $77.8-80.7$ & 76 & $74.5-77.0$ & 48 & $46.5-48.9$ \\
\hline Adherence assessment & 49 & $47.2-51.3$ & 86 & $84.6-87.2$ & 91 & $89.6-91.9$ & 75 & $72.3-77.4$ \\
\hline Hematocrit measurement & 15 & $14.0-17.0$ & 31 & $29.2-32.7$ & 36 & $34.2-38.0$ & 26 & $24.5-27.1$ \\
\hline Liver function test & 14 & $12.4-15.2$ & 23 & $21.1-24.4$ & 29 & $26.8-30.3$ & 28 & $27.1-29.7$ \\
\hline Hepatitis screening & 16 & $15.1-17.4$ & 27 & $25.3-27.9$ & 44 & $42.2-45.1$ & 55 & $53.4-56.7$ \\
\hline Care and support assessment & 20 & $18.6-21.1$ & 48 & $46.2-49.1$ & 74 & $72.7-76.0$ & 80 & $78.8-81.5$ \\
\hline Nutritional assessment & 28 & $26.4-30.6$ & 81 & $79.0-82.4$ & 81 & $79.7-82.9$ & 93 & $91.3-93.7$ \\
\hline 1-year no visit & 31 & $29.8-32.8$ & 32 & $30.4-33.2$ & 37 & $36.0-38.9$ & 3 & $2.3-5.0$ \\
\hline Lost to follow up & 46 & $43.8-47.4$ & 36 & $34.8-38.1$ & 42 & $40.5-43.6$ & 12 & $10.6-12.8$ \\
\hline TB screening & & & 58 & $56.1-59.7$ & 73 & $71.7-75.0$ & 81 & $79.4-82.4$ \\
\hline
\end{tabular}

$\mathrm{Cl}$ confidence interval 


\section{Performance comparison of tertiary and secondary health} facilities

The baseline performance scores for most of the indicators were lower for secondary health facilities compared to tertiary except for hepatitis B screening, HIV/AIDS care and support assessment, and 1 year without clinical visit as shown in Table 2 . Across both tiers of the health care system, quality performance scores improved from baseline in 2008 to 2010. After 2010, there are declines in weight monitoring, adherence assessment, and hematocrit measurements. Compared to tertiary health facilities, the secondary facilities not only improved favorably but also surpass the highly specialized tertiary sites in almost all indicator domains except on HBV screening and hematocrit measurements.

The aggregated mean change in slope from 2008 to 2012 was higher for care and support assessment: 0.06 ( $^{\text {trend }}<0.01$ ); 3 months lost to follow up: 0.05 $\left(\mathrm{p}^{\text {trend }}<0.01\right)$. However, mean change of slopes for the secondary facilities over the 5 years was higher compared to tertiary facilities for liver function test (0.04 vs. $0.01)$, nutritional assessment (0.08 vs. 0.4$), 1$ year no visit $(-0.04$ vs. -0.01$)$ and tuberculosis screening $(0.04$ vs. 0.02 ). There is no difference in the mean change in slope between the two tiers for most of the quality indicators evaluated (Table 3).

\section{Discussion}

The approach adopted to evaluate HIV/AIDS quality management implementation in this study is the first of its kind in Nigeria. The assessment compared annual performance and trends of quality of services provided by HIV programs at clinic levels over a period of 5 years. To our knowledge, no similar analysis has been conducted in sub-Saharan Africa (sSA). Tertiary health facilities provide specialty services and represent the most specialized level in the healthcare delivery system. Our findings show that even though secondary health facilities may not provide as much high quality of services at the early years of an HIV program, they catch up and even surpass tertiary levels but over time as the program matures,

Improvement across all indicators from baseline in 2008 to 2010 was likely the result of planned activities designed to address deficiencies identified during the first two successive HIVQUAL-N cycles. The HIVQUAL$\mathrm{N}$ project implemented by IHV-UMB suffered a setback in 2011 following funding challenges and transition to a local IHV-Nigeria. The resultant delayed financial and technical support explain the decline in scores for weight monitoring, adherence assessment, and hematocrit monitoring, and only marginal improvement in the other areas in 2012. This is because these activities are conducted at clinic-level where the workload is often

Table 2 Percentage scores of HIV/AIDS quality indicators by health facility type from 2008 to 2012

\begin{tabular}{|c|c|c|c|c|c|c|c|c|c|}
\hline \multirow[t]{2}{*}{ Quality indicators } & \multirow[t]{2}{*}{ Facility type } & \multicolumn{2}{|c|}{2008} & \multicolumn{2}{|c|}{2009} & \multicolumn{2}{|c|}{2010} & \multicolumn{2}{|c|}{2012} \\
\hline & & $\%$ & $95 \% \mathrm{Cl}$ & $\%$ & $95 \% \mathrm{Cl}$ & $\%$ & $95 \% \mathrm{Cl}$ & $\%$ & $95 \% \mathrm{Cl}$ \\
\hline \multirow[t]{2}{*}{ Weight monitoring } & $3^{0}$ & 78 & $75.8-79.1$ & 79 & $77.3-80.4$ & 77 & $74.9-78.2$ & 48 & $46.4-49.0$ \\
\hline & $2^{0}$ & 65 & $58.0-70.7$ & 83 & $77.7-86.7$ & 72 & $65.7-77.3$ & 48 & $44.0-52.5$ \\
\hline \multirow[t]{2}{*}{ Adherence assessment } & $3^{0}$ & 48 & $45.6-49.8$ & 86 & $84.3-87.1$ & 91 & $89.9-92.3$ & 73 & $70.8-75.8$ \\
\hline & $2^{0}$ & 68 & $60.4-74.4$ & 87 & $82.4-91.2$ & 87 & $81.5-90.9$ & 92 & $85.0-95.5$ \\
\hline \multirow[t]{2}{*}{ Hematocrit measurement } & $3^{0}$ & 16 & $14.2-17.3$ & 32 & $29.7-33.5$ & 37 & $34.8-388$ & 26 & $24.7-27.5$ \\
\hline & $2^{0}$ & 12 & $7.9-17.8$ & 25 & $19.5-30.8$ & 29 & $23.2-35.6$ & 22 & $17.9-26.8$ \\
\hline \multirow[t]{2}{*}{ Liver function test } & $3^{0}$ & 15 & $13.3-16.2$ & 23 & $21.1-24.5$ & 29 & $27.1-30.8$ & 28 & $26.8-29.6$ \\
\hline & $2^{0}$ & 3 & $1.3-7.3$ & 22 & $17.2-28.1$ & 25 & $19.4-31.3$ & 30 & $25.4-34.7$ \\
\hline \multirow[t]{2}{*}{ Hepatitis screening } & $3^{0}$ & 16 & $14.8-17.2$ & 28 & $26.3-29.0$ & 46 & $44.2-47.3$ & 55 & $53.5-57.0$ \\
\hline & $2^{0}$ & 18 & $14.2-23.3$ & 17 & $13.4-20.6$ & 24 & $20.4-28.6$ & 52 & $46.5-58.2$ \\
\hline \multirow[t]{2}{*}{ Care and support assessment } & $3^{0}$ & 19 & $18.1-20.6$ & 47 & $45.7-48.8$ & 76 & $74.0-77.4$ & 79 & $78.0-80.9$ \\
\hline & $2^{0}$ & 25 & $21.1-30.3$ & 51 & $46.3-55.7$ & 60 & $54.0-66.5$ & 88 & $83.6-91.4$ \\
\hline \multirow[t]{2}{*}{ Nutritional assessment } & $3^{0}$ & 31 & $28.6-33.1$ & 82 & $80.4-83.8$ & 83 & $81.7-84.8$ & 92 & $90.4-93.1$ \\
\hline & $2^{0}$ & 5 & $1.9-8.9$ & 69 & $62.7-75.0$ & 58 & $50.4-65.0$ & 100 & $97.4-1.0$ \\
\hline \multirow[t]{2}{*}{1 year no-visit } & $3^{0}$ & 30 & $28.6-31.6$ & 31 & $29.9-32.8$ & 37 & $35.1-38.1$ & 4 & $2.5-5.8$ \\
\hline & $2^{0}$ & 43 & $37.9-48.5$ & 35 & $30.8-39.8$ & 45 & $40.8-50.2$ & 1 & $0.2-5.4$ \\
\hline \multirow[t]{2}{*}{3 months loss to follow-up } & $3^{0}$ & 46 & $44.2-48.0$ & 36 & $34.6-38.1$ & 42 & $40.2-43.5$ & 12 & $10.9-13.3$ \\
\hline & $2^{0}$ & 40 & $33.1-46.5$ & 37 & $31.3-42.6$ & 44 & $39.4-49.2$ & 7 & $4.4-11.0$ \\
\hline \multirow[t]{2}{*}{ TB Screening } & $3^{0}$ & - & & 57 & $55.3-59.0$ & 77 & $75.1-78.5$ & 80 & $78.0-81.1$ \\
\hline & $2^{0}$ & - & & 65 & $59.5-70.7$ & 38 & $31.7-44.1$ & 96 & $92.0-97.8$ \\
\hline
\end{tabular}

$3^{0}$, tertiary health care facility; $2^{0}$, secondary health care facility 
Table 3 Rate of change of ( $\beta$ ) HIV/AIDS quality indicators trend for tertiary and secondary health facilities over the 5 -year review period

\begin{tabular}{|c|c|c|c|c|c|c|}
\hline \multirow[t]{2}{*}{ Quality indicators } & \multicolumn{3}{|c|}{ Rate of change $(\beta)$ per year } & \multicolumn{3}{|c|}{$\mathrm{p}$-value for trend } \\
\hline & Aggregated & Tertiary & Secondary & Aggregated & Tertiary & Secondary \\
\hline Weight monitoring & -0.03 & -0.03 & -0.03 & $<0.01$ & $<0.01$ & $<0.001$ \\
\hline ART adherence assessment & 0.02 & 0.02 & 0.02 & $<0.01$ & $<0.01$ & 0.13 \\
\hline Hematocrit measurement & 0.01 & 0.01 & 0.01 & $<0.01$ & 0.01 & 0.23 \\
\hline Liver function test & 0.02 & 0.01 & 0.04 & $<0.01$ & $<0.01$ & $<0.01$ \\
\hline Hepatitis serology & 0.05 & 0.05 & 0.05 & $<0.01$ & $<0.01$ & $<0.01$ \\
\hline HIV/AIDS care and support & 0.06 & 0.06 & 0.06 & $<0.01$ & $<0.01$ & $<0.01$ \\
\hline Nutritional assessment & 0.05 & 0.04 & 0.08 & $<0.01$ & $<0.01$ & $<0.01$ \\
\hline 1 year no visit & -0.02 & -0.01 & -0.04 & $<0.01$ & $<0.01$ & $<0.01$ \\
\hline 3 months loss-to-follow up & -0.05 & -0.05 & -0.05 & $<0.01$ & $<0.01$ & $<0.01$ \\
\hline Tuberculosis screening & 0.02 & 0.02 & 0.04 & $<0.01$ & $<0.01$ & $<0.01$ \\
\hline
\end{tabular}

enormous. Indicators measured outside the HIV/AIDS clinics demonstrated better improvement over the same period.

The decline in loss to follow-up, especially from a peak of $42 \%$ in 2010 in tertiary health facilities, to $12 \%$, corresponds with findings from a longitudinal analysis of risk factors of patient retention and adherence to ARVs where the loss to follow-up rate was reported as $26 \%$ [19].

Generally, it is observed that scores for most of the quality indicators are almost at par between tertiary and secondary levels of care from 2008 to 2010 . However, by the last review in 2012, the secondary level of healthcare recorded better improvement than the tertiary level in every quality indicator except for anemia screening (hematocrit measurement) and hepatitis serology, where the difference in scores is also marginal. These findings have programmatic implications for decentralizing HIV/ AIDS services to more peripheral health centers such as secondary and primary facilities.

Other studies have shown that the quality of care is preserved when decentralization occurs. A study of patients' demographic and clinical characteristics and level of care associated with loss to follow-up and mortality in adult patients on first-line ART in Nigerian hospitals, also found that retention of patients is better at secondary health facilities compared to tertiary over a period of 36 months [20]. A report from South Africa found that decentralization to lower clinic levels provided greater proximity and acceptability of services leading to faster enrollment of access to ART and better retention with loss to follow-up reduction from 19 to $2 \%$ [21]. Another study in Malawi demonstrated the feasibility of district-wide access to ART in a setting with limited resources for health. Expansion and decentralization of HIV/AIDS service-capacity to primary care level, combined with task shifting, resulted in increased access to HIV services with good program outcomes despite staff shortages [22].

The application of HIVQUAL model to measure of HIV/AIDS quality of service appears adoptable in a resource-limited setting and should be expanded to cover not only treatment, care and support services, but also prevention services, especially elimination of mother to child transmission of HIV and community ART services and palliative care. Similarly, performance measurements for quality indicators should be conducted on a regular schedule in order to consolidate and build upon improvements achieved. It has been shown in this study that temporary breach of a schedule pattern as can be caused by a lack of or inadequate funding and technical support, can cause tremendous setbacks and compromise all gains recorded. This strongly underscores the value of continuous measurement as a stimulus to driving improvement in clinics to sustain gains in performance.

\section{Abbreviations}

ACTION: AIDS Care and Treatment in Nigeria; AIDS: Acquired Immuno-

Deficiency Syndrome; ART: anti-retroviral therapy; ARV: anti-retroviral; Cl: confidence interval; CQI: continuous quality improvement; FMoH: Federal Ministry of Health; GFTAM: Global Fund for AIDS, Tuberculosis, and Malaria; HIV: human immune-deficiency virus; HIVQUAL: human immune-deficiency virus quality; HIVQUAL-N: human immune-deficiency virus quality-Nigeria; HRSA: Health Resources Services Administration; IHV/UMB: Institute of Human Virology/ University of Maryland Baltimore; IHVN: Institute of Human Virology Nigeria; LFT: liver function test; NHREC: National Health Research Ethics Committee; NYSDOH-AI: New York State Department of Health-AIDS Institute; PEPFAR: Presidents'Emergency Plan for AIDS Relief; SSA: sub-Saharan Africa; p: p-value; PEPFAR: President's Emergency Plan for AIDS Relief; PLHIV: People living with Human Immunodeficiency Virus; QoC: quality of care; QoL: quality of life.

\section{Acknowledgements}

I wish to acknowledge Nwaneka Okereke and Chinenye Ugoji for providing access to the data used in this study. 


\section{Authors' contributions}

$A A$ and $M C$ are the principal investigators for the study. They contributed to the study design, data collection, and analysis as well as drafted the initial and revised manuscripts. All the remaining authors contributed to the data collection, data analysis and made critical inputs into the revision and finalization of the manuscript. All authors read and approved the final manuscript.

\section{Funding}

This research was supported by the United States National Institute of Health, Fogarty program and Institute of Human Virology, University of Maryland School of Medicine. All findings, contents and conclusions from this paper do not represent the view or official position of NIH, PEPFAR or University of Maryland Baltimore.

\section{Availability of data and materials}

The datasets generated and/or analysed in the study are not publicly available due to institutional policy but are available from the corresponding author on reasonable request.

\section{Ethics approval and consent to participate}

The study was approved by the University of Maryland Baltimore, School of Medicine, as well as a program-wide Institutional Review Board approval of National Human Research Ethics Committee (NHREC). The data analysed and presented in the manuscript were originally collected in the medical record of each of the facilities involved as part of routine medical care/program activities. Informed consent was not required from patients since recording of data into the medical charts/ database was routine for regular medical care and program implementation.

\section{Consent for publication}

Not applicable.

\section{Competing interests}

The authors declare that they have no competing interests.

\section{Author details}

${ }^{1}$ Institute of Human Virology, Nigeria, Maina Court, Plot 252 Herbert Macaulay Way, Central Business District, Garki, Abuja 9396, Nigeria. ${ }^{2}$ Department of Epidemiology and Public Health, University Maryland School of Medicine, Baltimore, USA. ${ }^{3}$ Institute for Global Health Sciences, University of California San Francisco, San Francisco, USA. ${ }^{4}$ Institute of Human Virology, University of Maryland School of Medicine, Baltimore, USA. ${ }^{5}$ Institute of Human Virology, Nigeria (IHVN), Abuja, Nigeria. ${ }^{6}$ Academy for Health and Development, lle-Ife, Nigeria. ${ }^{7}$ Department of Medicine, University of Maryland School of Medicine, 725 West Lombard Street, Baltimore, Maryland 21201, USA.

\section{Appendix 1}

See Table 4.

\section{Table 4 Quality of care indicators for performance evaluation in HIV Quality Nigeria project}

\begin{tabular}{ll}
\hline Indicator & Definition \\
\hline $\begin{array}{l}\text { 1-year no visit } \\
3 \text { months loss to follow-up }\end{array}$ & $\begin{array}{l}\text { Proportion of HIV patients who had no visit in the review year (or period) } \\
\text { Proportion of patients on ART who had no visit in the last } 3 \text { months of the review year (or period) } \\
\text { Proportion of HIV patients on a Nevirapine (NVP)-containing regimen with at least one liver function test (LFT) } \\
\text { in the past } 12 \text { months }\end{array}$ \\
$\begin{array}{ll}\text { Hematocrit measurement } \\
\text { Proportion of HIV patients on a Zidovudine (ZDV)-containing regimen with at least one hematocrit in the past } \\
\text { Hepatitis serology }\end{array}$ & $\begin{array}{l}\text { Proportion of HIV patients who have ever had hepatitis serology testing } \\
\text { Tuberculosis screening }\end{array}$ \\
$\begin{array}{l}\text { Peight monitoring } \\
\text { Adherence assessments }\end{array}$ & Proportion of HIV patients whose weight is recorded in the past 6 months \\
Care and support assessment & Proportion of HIV patients who have documented care and support assessment during the review period \\
Nutritional assessment & Proportion of HIV patients who have documented nutritional assessment in the review period \\
\hline
\end{tabular}




\section{Appendix 2}

\section{See Fig. 1.}
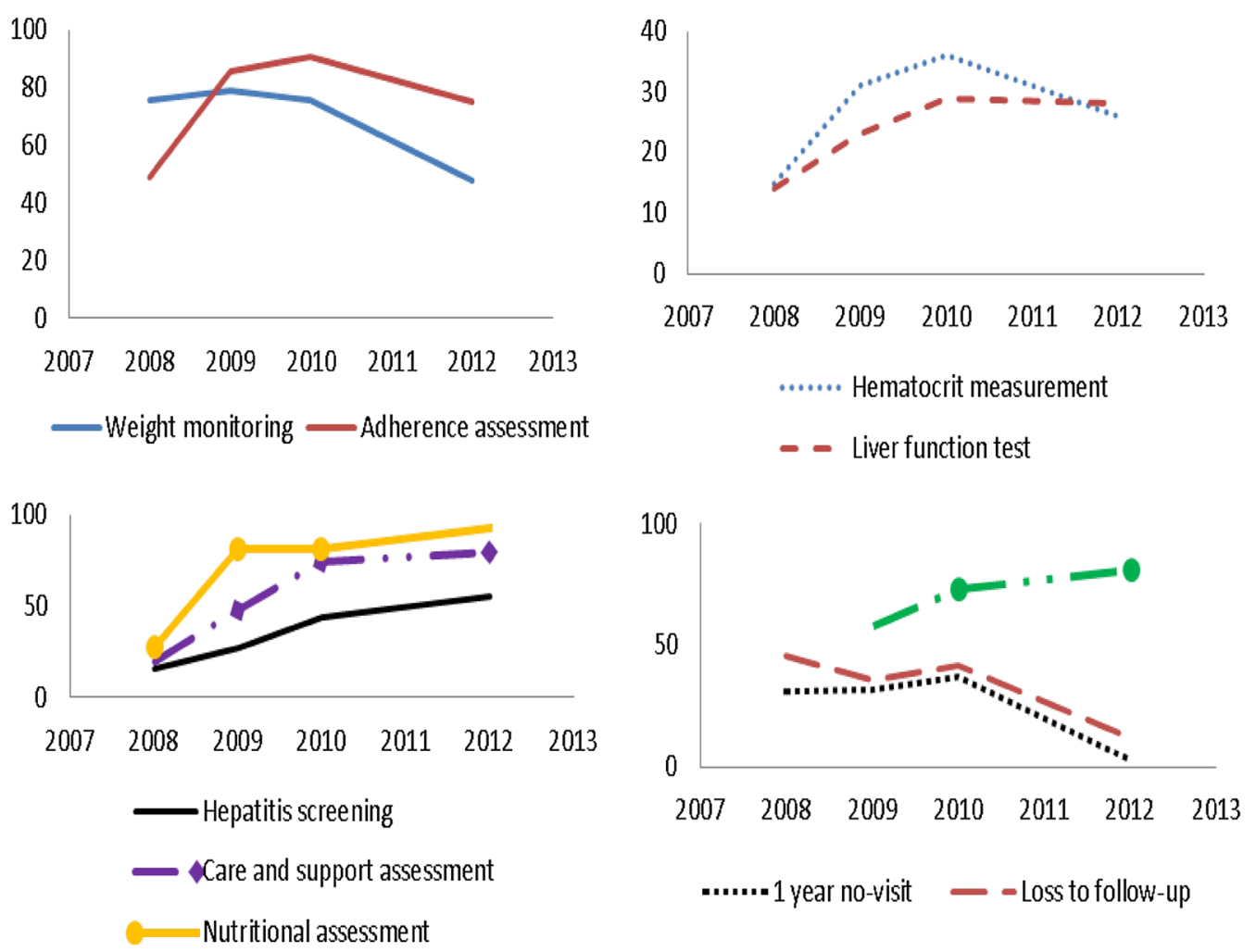

Fig. 1 Health facilities performance trends of HIV/AIDS quality indicators in HIVQUAL Nigeria from 2008 to 2012

Received: 26 March 2019 Accepted: 29 August 2019

Published online: 01 October 2019

\section{References}

1. UNAIDS. UNAIDS Data Tables. 2017. http://aidsinfo.unaids.org/.

2. Idigbe EO, Adewole TA, Eisen G, Kanki P, Odunukwe NN, et al. Management of HIV-1 infection with a combination of nevirapine, stavudine, and lamivudine: a preliminary report on the Nigerian antiretroviral program. J Acquir Immune Defic Syndr. 2005;40:65-9.

3. Mocroft A, Lundgren JD. Starting highly active antiretroviral therapy: why, when and response to HAART. J Antimicrob Chemother. 2004:54:10-3.

4. Monjok E, Smesny A, Okokon IB, Mgbere O, Essien EJ. Adherence to antiretroviral therapy in Nigeria: an overview of research studies and implications for policy and practice. HIV/AIDS. 2010;2:69-76.

5. Dube MP, Sattler FR. Inflammation and complications of HIV disease. J Infect Dis. 2010;201:1783-5.

6. Brooks JT, Kaplan JE, Holmes KK, Benson C, Pau A, et al. HIV-associated opportunistic infections-going, going, but not gone: the continued need for prevention and treatment guidelines. Clin Infect Dis. 2009;48:609-11.

7. Nigeria Population (2018-02-24). http://worldpopulationreview.com/ countries/Nigeria/.

8. Gakhar H, Kamali A, Holodniy M. Health-related quality of life assessment after antiretroviral therapy: a review of the literature. Drugs. 2013:73:651-72

9. Brent RJ. The effects of HIV medications on the quality of life of older adults in New York City. Health Econ. 2012;21:967-76.
10. Mekuria LA, Sprangers MA, Prins JM, Yalew AW, Nieuwkerk PT. Healthrelated quality of life of HIV-infected adults receiving combination antiretroviral therapy in Addis Ababa. AIDS Care. 2015;27:934-45.

11. Jia H, Uphold CR, Wu S, Chen GJ, Duncan PW. Predictors of changes in health-related quality of life among men with HIV infection in the HAART era. AIDS Patient Care STDs. 2005:19:395-405.

12. Wood E, Hogg RS, Yip B, Harrigan PR, O'Shaughnessy MV, et al. Effect of medication adherence on survival of HIV-infected adults who start highly active antiretroviral therapy when the CD4+ cell count is 0.200 to $0.350 \times 10(9)$ cells/L. Ann Intern Med. 2003;139:810-6.

13. Palella FJ Jr, Deloria-Knoll M, Chmiel JS, Moorman AC, Wood KC, et al. Survival benefit of initiating antiretroviral therapy in HIV-infected persons in different CD4+ cell strata. Ann Intern Med. 2003;138:620-6.

14. Liu C, Weber K, Robison E, Hu Z, Jacobson LP, et al. Assessing the effect of HAART on change in quality of life among HIV-infected women. AIDS Res Ther. 2006;3:6.

15. Kitahata MM, Tegger MK, Wagner EH, Holmes KK. Comprehensive health care for people infected with HIV in developing countries. BMJ. 2002:325:954-7.

16. Uzochukwu BS, Onwujekwe OE, Onoka AC, Okoli C, Uguru NP, et al. Determinants of non-adherence to subsidized anti-retroviral treatment in southeast Nigeria. Health Policy Plan. 2009;24:189-96.

17. Ahonkhai AA, Bassett IV, Ferris TG, Freedberg KA. Improving HIV outcomes in resource-limited countries: the importance of quality indicators. BMC Health Serv Res. 2012;12:427.

18. Hanna M, Minga A, Fao P, Borand L, Diouf A, et al. Development of a checklist of quality indicators for clinical trials in resource-limited 
countries: the French National Agency for Research on AIDS and Viral Hepatitis (ANRS) experience. Clin Trials. 2013;10:300-18.

19. Charurat M, Oyegunle M, Benjamin R, Habib A, Eze E, et al. Patient retention and adherence to antiretrovirals in a large antiretroviral therapy program in Nigeria: a longitudinal analysis for risk factors. PLoS ONE. 2010;5:e10584.

20. Odafe S, Idoko O, Badru T, Aiyenigba B, Suzuki C, et al. Patients' demographic and clinical characteristics and level of care associated with lost to follow-up and mortality in adult patients on first-line ART in Nigerian hospitals. J Int AIDS Soc. 2012;15:17424.

21. Bedelu M, Ford N, Hilderbrand K, Reuter H. Implementing antiretroviral therapy in rural communities: the Lusikisiki model of decentralized HIV/ AIDS care. J Infect Dis. 2007;196(Suppl 3):S464-8.
22. Bemelmans $M$, van den Akker T, Ford N, Philips M, Zachariah R, et al. Providing universal access to antiretroviral therapy in Thyolo, Malawi through task shifting and decentralization of HIV/AIDS care. Trop Med Int Health. 2010;15:1413-20.

\section{Publisher's Note}

Springer Nature remains neutral with regard to jurisdictional claims in published maps and institutional affiliations.
Ready to submit your research? Choose BMC and benefit from:

- fast, convenient online submission

- thorough peer review by experienced researchers in your field

- rapid publication on acceptance

- support for research data, including large and complex data types

- gold Open Access which fosters wider collaboration and increased citations

- maximum visibility for your research: over 100M website views per year

At BMC, research is always in progress.

Learn more biomedcentral.com/submissions 